\title{
Update on benign convulsions with mild gastroenteritis
}

Yeong Seok Lee, MD, Ga Hee Lee, MD, Young Se Kwon, MD

Department of Pediatrics, School of Medicine, Inha University, Incheon, Korea
Benign convulsions with mild gastroenteritis $(\mathrm{CwG})$ are characterized by afebrile convulsions associated with viral gastroenteritis in previously healthy infants and children. The main causative pathogens are rotavirus and norovirus. $\mathrm{CwG}$ occurs frequently in both East Asian and Western countries. The prevalence of $\mathrm{CwG}$ was reportedly not decreased by the introduction of rotavirus vaccines, and the prevalence of norovirus-associated $\mathrm{CwG}$ has been increasing annually. Convulsions in CwG are usually clustered, do not last longer than 5 minutes, and are mostly generalized. Laboratory diagnostics, electroencephalography (EEG), and imaging findings are usually normal. There is a probability of mild, transient abnormal findings on EEG or imaging limited to the acute disease phase. Although several reports have suggested that pathogens that affect the central nervous system through direct or indirect mechanisms could be related to the pathophysiology of $\mathrm{CwG}$, its mechanism is not fully understood. Several antiepileptic drugs are effective during convulsions; however, long-term antiepileptic treatment is not required as $\mathrm{CwG}$ usually has a good prognosis.

Key words: Seizures, Gastroenteritis, Rotavirus, Norovirus

\section{Key message}

- The main pathogen for benign convulsions with mild gastroenteritis $(\mathrm{CwG})$ was previously rotavirus; however, cases associated with norovirus are increasing.

- $\mathrm{CwG}$ is characterized by clustered generalized seizures. Electroencephalography and magnetic resonance imaging show transiently abnormal findings in the acute phase that eventually normalize with progression. Its prognosis is good, and longterm treatment is unnecessary.

- There are many reports on the pathophysiological mechanism of $\mathrm{CwG}$, which remains unclear.

\section{Introduction}

Acute gastroenteritis (AGE) is a common disease in pediatric patients, affecting more than 100 million children annually and sometimes requiring hospitalization. ${ }^{1,2)}$ Rotavirus and noro- virus are the main causes of AGE, and several reports have shown that these viruses can cause central nervous system (CNS) complications such as meningitis, encephalitis, and encephalopathy. ${ }^{3-7)}$

Benign convulsions with mild gastroenteritis $(\mathrm{CwG})$ was first reported by Morooka ${ }^{8)}$ in 1982 as mild gastroenteritis that causes convulsions without fever, severe dehydration, electrolyte imbalance, and hypoglycemia. In 1995, Komori et al..$^{9)}$ reported the following characteristics: (1) afebrile convulsions generated within 5 days of acute viral gastroenteritis in previously healthy infants and children between the ages of 6 months and 3 years; (2) absence of moderate or severe dehydration; (3) possible recurrence of seizures over several days; (4) normal serum electrolyte levels, cerebrospinal fluid (CSF) analysis results, and blood glucose level; (5) a good prognosis; and (6) usually caused by rotavirus. Since then, several reports have broadened the range of definitions for patients aged $<6$ years with $\mathrm{CwG}$. ${ }^{10-16)}$ $\mathrm{CwG}$ is frequently reported in East Asian countries as well as in the United States and Europe. ${ }^{17,18)}$

After the introduction of rotavirus vaccines, some changes in epidemiology and clinical characteristics occurred in rotavirusassociated $\mathrm{CwG}(\mathrm{RaCwG})$ as well as norovirus-associated $\mathrm{CwG}(\mathrm{NaCwG}) .{ }^{12,13,18,19)}$ There have also been several recent reports on the diagnosis and treatment of $\mathrm{CwG}^{20-22)}$ Therefore, this review includes recent reports of $\mathrm{CwG}$ and covers the epidemiology, clinical manifestations, pathophysiology, biomarkers, and treatment with the aim of promoting the recognition and management of $\mathrm{CwG}$.

\section{Epidemiology}

The ratio of $\mathrm{RaCwG}$ to rotavirus gastroenteritis (RVGE) is approximately $1.29 \%$ to $5.5 \%$ (Table 1). ${ }^{12,13,19} 23,24$ ) The ratio of $\mathrm{RaCwG}$ to $\mathrm{CwG}$ was reportedly $48.4 \%$ to $55.8 \%$, but the data in these reports were compiled before rotavirus vaccines were widely used. ${ }^{17,25)}$ One study showed that the ratio of $\mathrm{NaCwG}$ to NVGE was higher than that of RaCwG to RVGE. ${ }^{24)}$ However, other studies reported a lower ratio. ${ }^{13)}$ Meanwhile, the ratio of $\mathrm{NaCwG}$ to $\mathrm{CwG}$ was reportedly $14.5 \%$ prior to the introduction of rotavirus vaccines ${ }^{25)}$ and $63.04 \%$ thereafter. ${ }^{15)}$

Corresponding author: Young Se Kwon, MD, PhD. Department of Pediatrics, School of Medicine, Inha University, 27 Inhang-ro, Jung-gu, Incheon 22332, Korea 凶Email: ysped@inha.ac.kr, https://orcid.org/0000-0003-4570-7037

Received: 21 July 2021, Revised: 27 October 2021, Accepted: 15 December 2021

This is an open-access article distributed under the terms of the Creative Commons Attribution Non-Commercial License (http://creativecommons.org/licenses/bync/4.0/) which permits unrestricted non-commercial use, distribution, and reproduction in any medium, provided the original work is properly cited.

Copyright (c) 2022 by The Korean Pediatric Society 


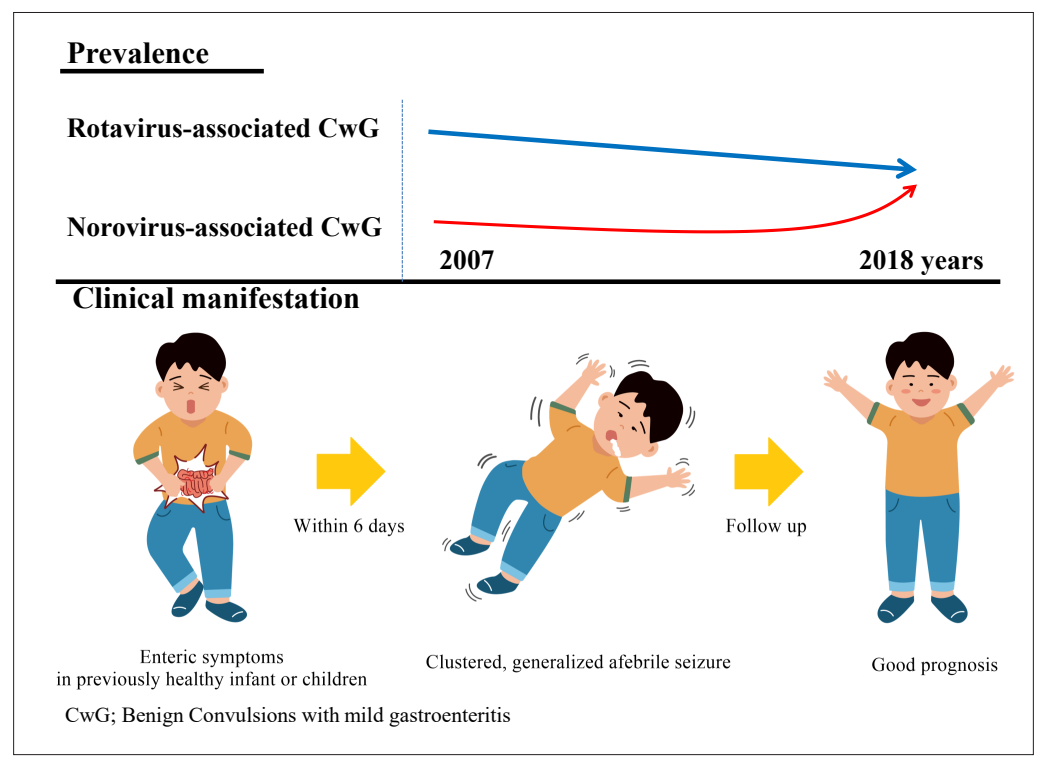

Graphical abstract

Table 1. Studies of the epidemiology of CwG published in the last 10 years

\begin{tabular}{|c|c|c|c|c|c|c|}
\hline Study & Year & Main pathogens & Age (yr) & Sex ratio (male:female) & Seasonality & Ratio \\
\hline Kim et al. ${ }^{12)}$ & 2020 & Rotavirus & $0^{\text {b) }}$ & $1: 0.9$ & NS & $0.024 \%^{f)}$ \\
\hline Kim et al. ${ }^{13)}$ & 2021 & Rotavirus, norovirus & $\begin{array}{l}0\left(\mathrm{RaCWG}^{\mathrm{b})}\right. \\
1(\mathrm{NaCWG})^{b)}\end{array}$ & $\begin{array}{l}1: 0.9 \text { (RaCwG) } \\
1: 0.8(\mathrm{NaCwG})\end{array}$ & $\begin{array}{l}\text { Wniter and spring (RaCwG) } \\
\text { Winter (NaCwG) }\end{array}$ & $0.013 \%^{f)}$ \\
\hline Kim et al. ${ }^{14)}$ & 2018 & Rotavirus, norovirus & $\begin{array}{l}1.6(\mathrm{RaCwG})^{\mathrm{a})} \\
1.6(\mathrm{NaCwG})^{\mathrm{a})}\end{array}$ & $\begin{array}{l}1: 1 \text { (RaCwG) } \\
1: 2.6 \text { (NaCwG) }\end{array}$ & Winter & $\begin{array}{l}18.6 \%^{\mathrm{d})} \\
31.4 \%{ }^{\mathrm{e}}\end{array}$ \\
\hline Kim et al. ${ }^{15)}$ & 2016 & Norovirus & $1.6^{\mathrm{a})}$ & $1: 2.2$ & Winter & $63.04 \%{ }^{\mathrm{e}}$ \\
\hline Lee et al. ${ }^{19)}$ & 2021 & Rotavirus & $1.9^{\mathrm{b})}$ & $1: 1.1$ & Winter and spring & $2.4 \%{ }^{c)}$ \\
\hline Kang et al. ${ }^{23)}$ & 2013 & Rotavirus & $1.76^{\mathrm{a})}$ & $1: 1.8$ & NS & $5.6 \%{ }^{c)}$ \\
\hline Ma et al. ${ }^{34)}$ & 2019 & Rotavirus & NS & $1: 0.7$ & $\begin{array}{l}\text { Fall and winter ( } \mathrm{RaCwG}) \\
\text { No seasonality ( } \mathrm{NaCwG})\end{array}$ & $\begin{array}{l}38.2 \%{ }^{\mathrm{d})} \\
12.7 \%{ }^{\mathrm{e}}\end{array}$ \\
\hline
\end{tabular}

CwG, benign convulsions with mild gastroenteritis; NS, not studied; RaCwG, rotavirus-associated benign convulsions with mild gastroenteritis; NaCwG, norovirus-associated benign convulsions with mild gastroenteritis.

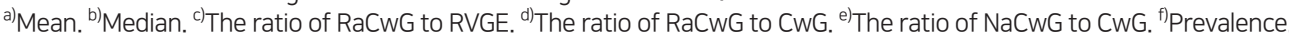

Our recent study of nationwide data from health insurance reviews and associated services in South Korea showed that the prevalence of RaCwG was $0.013 \%-0.024 \%$ and that of $\mathrm{NaCwG}$ was $0.00001 \% .{ }^{12,13)}$ We also found that the annual prevalence of RVGE decreased significantly after rotavirus vaccines were introduced in Korea; however, the prevalence of $\mathrm{RaCwG}$ did not change. In contrast, the annual prevalence of $\mathrm{NaCwG}$ is increasing (Fig. 1). ${ }^{12,13)}$ Geographically, the prevalence of RVGE decreased irrespective of the region after the introduction of rotavirus vaccines, but the ratio of $\mathrm{RaCwG}$ to RVGE increased in urban areas (Fig. 2). ${ }^{12)}$ However, these studies have limitations because they did not compile data directly from patient charts; rather, they defined patients using only diagnostic codes. Therefore, further multicenter trials are necessary to determine the actual prevalence of these conditions.

CwG commonly occurs in children aged $<6$ years and peaks at age 12-24 months. ${ }^{10-15,17,25-36)}$ The ratio of male to female patients with CwG was reportedly 1:0.7-2.6. ${ }^{11,15,17,27-36)} \mathrm{In}$ addition, it mainly occurs between October and May. ${ }^{11,15,17,28,30)}$

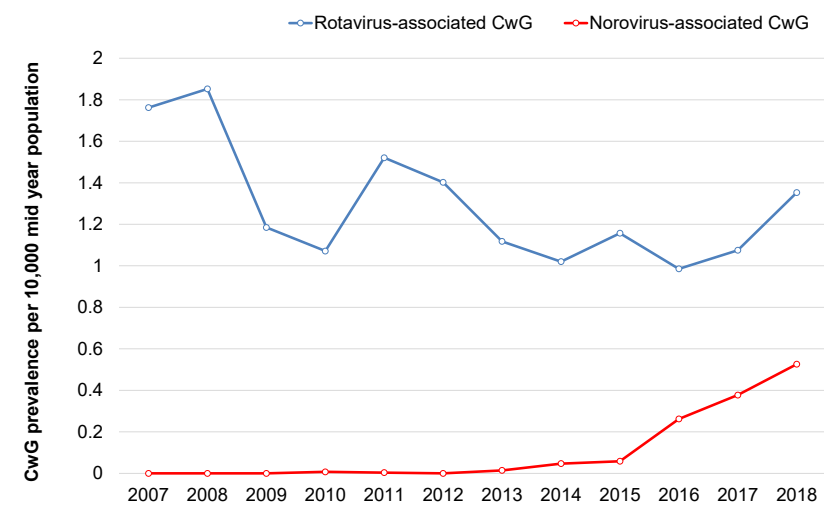

Fig. 1. Annual changes of the rotavirus- and norovirus-associated benign convulsions with mild gastroenteritis (RaCwG and NaCwG, respectively) prevalence per 100 mid-year population. Modified from Kim et al. Children (Basel) 2021;8:263. ${ }^{13}$

The proportion of patients with CwG and a family history of epilepsy or febrile seizure was 9.1\%-17.1\%. ${ }^{11,23,31,33,34,36}$

After rotavirus vaccination, the age at $\mathrm{RaCwG}$ onset repor- 


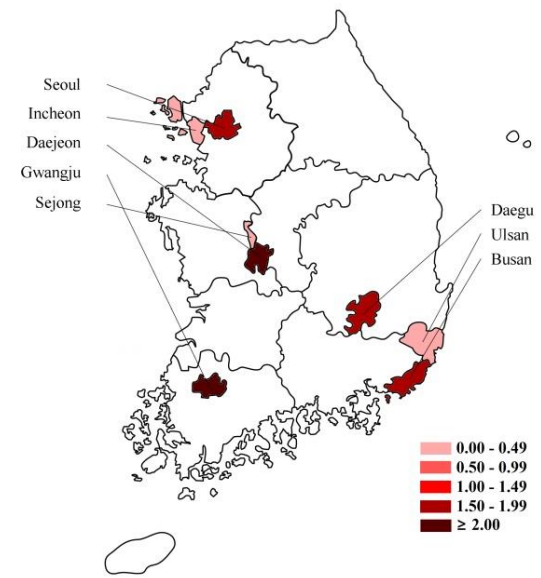

A

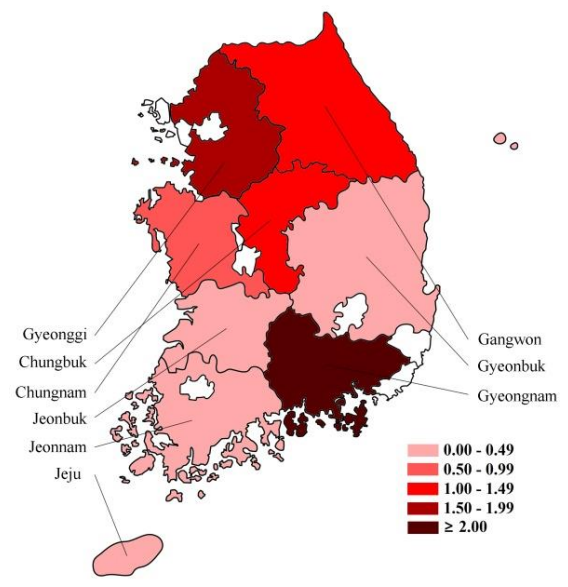

B

Fig. 2. The regional ratio of rotavirus-associated benign convulsions with mild gastroenteritis (RaCwG) to 100 rotavirus gastroenteritis (RVGE) patients and annual changes in the RaCwG prevalence in Korea. (A) Ratio of RaCwG to 100 RVGE patients in urban areas in 2018. (B) Ratio of RaCwG to 100 RVGE patients in rural areas in 2018. Modified from Kim et al. Int J Environ Res Public Health 2020;17:8374. ${ }^{12)}$

tedly increased. ${ }^{19)}$ Comparisons between $\mathrm{RaCwG}$ and $\mathrm{NaCwG}$ showed that the ratio of males to females with $\mathrm{RaCwG}$ was 1:0.9-1. ${ }^{8,10,12,13,19,23)}$ while that of those with $\mathrm{NaCwG}$ was 1:1.2-2.2. ${ }^{13,15)} \mathrm{RaCwG}$ commonly occurred between December and April, especially in winter ${ }^{10,14,19)}$ while $\mathrm{NaCwG}$ commonly occurred between November and December. $\mathrm{NaCwG}$ was less prevalent than $\mathrm{RaCwG}$ in spring. ${ }^{14,15)}$

\section{Clinical manifestations}

In $\mathrm{CwG}$, seizures occur within 6 days of intestinal symptoms. 11,14,15,17,23,27,28,30,31,33,36) The interval between enteric symptom onset and seizure onset was reportedly longer in $\mathrm{RaCwG}$ than in $\mathrm{NaCwG}^{14)}$ and in $\mathrm{RaCwG}$ than in febrile seizures associated with rotavirus infection. ${ }^{23)}$

One of the clinical characteristics of $\mathrm{CwG}$ is that between $2-4$ and up to 20 episodes of clustered seizures occur, ${ }^{11,14,15,17 \text {, }}$ 23,28,30,31,34,36) and 35\%-70.9\% of CwG patients experienced clustered seizures within 24 hours of viral infection. . $^{27,33-35)}$ The number of clustered seizures and total seizure frequency in $\mathrm{CwG}$ was greater than the number of febrile seizures with gastroenteritis. ${ }^{31)}$

Each seizure episode usually lasts less than 5 minutes. ${ }^{11,15,17 \text {, }}$ 23,27-31,34-36) Seizure semiology in CwG is mostly generalized, although focal seizures are occasionally reported. $11,15,17,23,27-31,34-$ 36) In particular, focal seizures were more frequently observed in patients with $\mathrm{CwG}$ than febrile seizures in patients with gastroenteritis. ${ }^{31)}$ Seizure relapse was also reported in $\mathrm{CwG}$ at a rate of approximately $4.7 \%-7.7 \%$; however, there were no cases of the subsequent development of epilepsy following CwG. ${ }^{11,32,33)}$

Although one of the characteristics of $\mathrm{CwG}$ is no abnormal findings in laboratory tests, some authors have conducted research with broader characteristic criteria of $\mathrm{CwG} .{ }^{11,17,30)} \mathrm{Se}$ - veral studies demonstrated that $\mathrm{CwG}$ may be associated with hyperuricemia or hyponatremia. ${ }^{29,34,37)} \mathrm{A}$ recent study found that severe ketosis occurring in patients with $\mathrm{CwG}$ is associated with lower blood glucose and sodium levels. ${ }^{35)}$ Serum aspartate aminotransferase levels were elevated in patients with $\mathrm{RaCwG}$ compared with patients with RVGE without seizures or patients with febrile seizure associated with RVGE. ${ }^{23)}$ Lower serum $\mathrm{Ca}^{2+}$ levels were also found in $\mathrm{RaCwG}$ patients $(9.22 \pm 0.50 \mathrm{mg})$ than in patients with rotavirus gastroenteritis without seizure $(9.66 \pm$ $0.46 \mathrm{mg}$ ); therefore, the author suggested that the disruption of $\mathrm{Ca}^{2+}$ homeostasis plays a critical role in triggering seizures. ${ }^{38)}$

Although electroencephalography (EEG) findings are usually normal in $\mathrm{CwG},{ }^{11,30)}$ some reports have shown abnormal EEG findings such as a focal onset of spikes and slow waves. 14,15,17,23,27,28,31,33,34) Abnormal EEG findings, mostly spikes in the asymmetric central region, are more frequent in $\mathrm{CwG}$ than in febrile seizures. ${ }^{31)}$ In addition, posterior slowing was observed more frequently in $\mathrm{NaCwG}$ than in $\mathrm{RaCwG} .{ }^{14)}$ However, these abnormal findings normalized during follow-up EEG taken 2-6 months later. ${ }^{31)}$

Brain magnetic resonance imaging (MRI) findings are usually normal; $11,17,27,28,30,31)$ however, some reports stated that focal abnormal lesions in the splenium of the corpus callosum appeared transiently. ${ }^{23,31,36,39-42)}$ In particular, rotavirus infection was a risk factor for splenial lesions in patients with $\mathrm{CwG}$. 36) A reversible splenial lesion on MRI resembles clinically mild encephalitis/encephalopathy with a reversible splenial lesion including the following diagnostic criteria: (1) onset of neuropsychiatric symptoms within one week after the onset of fever; (2) complete recovery without sequelae, mostly within 10 days after the onset of neuropsychiatric symptoms; (3) highsignal-intensity lesion in the splenium of the corpus callosum in the acute disease stage; (4) lesion that may involve the entire corpus callosum and the cerebral white matter in a symmetric fashion; and (5) lesion disappears within a week, with neither 
Table 2. Clinical characteristics of benign convulsions with mild gastroenteritis

\begin{tabular}{ll}
\hline Characteristic & \\
\hline Family history of epilepsy/febrile seizure & $9.1 \%-17.1 \%$ \\
Interval between enteric symptoms and first seizure & $0-6$ Days after enteric symptoms \\
Seizure type & Usually generalized seizures or focal seizures \\
Seizure frequency & Usually 2-4 episodes \\
Seizure duration & Usually within 5 minutes \\
Interval between the first and last seizure & Within 24 hours \\
Laboratory findings & Usually normal, hyperuricemia and relatively low levels of sodium or Ca ${ }^{2+}$ may be observed \\
Cerebrospinal fluid & Normal \\
Electroencephalogram & Usually normal \\
Radiological examinations & Usually normal \\
Prognosis & Good \\
\hline
\end{tabular}

residual signal changes nor atrophy. Therefore, caution is needed when diagnosing $\mathrm{CwG}$ with reversible splenial lesions. ${ }^{43-45)}$ Abnormal findings consistent with vasogenic edema were observed in $\mathrm{NaCwG},{ }^{46)}$ which normalized during the follow-up period (Table 2). ${ }^{36,39-42,46)}$

\section{Pathophysiology}

Despite many reports on the pathophysiological mechanism of $\mathrm{CwG}$, it remains unclear. Pathogens detected in $\mathrm{CwG}$ patients include rotavirus, norovirus, adenovirus, astrovirus, and sapovirus; of them, adenovirus, astrovirus, and sapovirus are rarely detected. ${ }^{14,15,47)}$ Several studies have attempted to identify the mechanisms of specific pathogens of rotavirus and norovirus. $^{3,47-57)}$ Rotavirus has 2 outer capsid proteins, VP4 and VP7, which are used to classify rotaviruses as $G$ and P genotypes. ${ }^{58)}$ Two studies investigated the association between the CwG and rotavirus genotypes, but they are controversial. Yang et al. ${ }^{47)}$ analyzed the genotypes of 13 patients with $\mathrm{RaCwG}$ and found that none were associated with the disease. However, Choi et al. ${ }^{48)}$ investigated rotavirus genotypes in 82 patients with rotavirus infection and found that G2P was significantly associated with neurologic complications. Thus, further largescale studies are required to clarify this relationship.

Several studies have sought to identify evidence regarding the direct invasion of rotavirus into the CNS. In the animal model and the sera of children, rotavirus antigenemia was confirmed. ${ }^{49-51)}$ This result suggests that rotavirus can penetrate the gastrointestinal tract and cause viremia. ${ }^{49,51)}$ Rotavirus has been shown to infect neuronal cells in vivo and in vitro, ${ }^{52,59)}$ and rotavirus RNA was detected in the CSF of patients with RVGE and convulsions. ${ }^{50,51)}$ Another hypothesis is that mediators may indirectly induce $\mathrm{CwG}$. One study showed that NO metabolite levels in the serum and CSF from rotavirus gastroenteritis patients with convulsions were much higher than those in patients with purulent meningitis, encephalitis, febrile convulsion, or in the healthy control group. ${ }^{60)}$ These findings indicate that NO may have a pathophysiological role in convulsions associated with rotavirus infection. Moreover, cytokines can indirectly affect the brain. Levels of interleukin (IL)-17 in particular are increased in convulsions following gastroenteritis versus rotavirus encephalopathy, indicating that IL-17 is a convulsion-related factor. ${ }^{61)}$ The endoplasmic reticulum-associated rotavirus protein, VP7, is used to indicate sorting signals to target vascular proteins on axons through nonclassical Golgi-independent mechanisms. These signals can also be detected in viral targets in different areas of the brain. ${ }^{52)}$ Nonstructural protein 4 (NSP4), a glycosylated protein of rotavirus, plays a leading role in the pathogenic mechanism of rotavirus by increasing cell membrane permeability to $\mathrm{Ca}^{2+} .{ }^{53)}$ Yeom et al. ${ }^{54)}$ investigated serum anti-NSP4[A] immunoglobulin $\mathrm{G}(\mathrm{IgG})$ and anti-NSP4[B] IgG in patients with RVGE and found that levels of both antibodies increased in the nonseizure versus seizure group. Therefore, the authors suggested that serum antiNSP4 IgG might protect against rotavirus-associated seizures.

On the other hand, some studies revealed the pathophysiology of norovirus-associated neurologic complications and found evidence of norovirus penetration into the gastrointestinal tract; in fact, its RNA was found in the serum and CSF., ${ }^{3,55-57)}$ However, research on the pathophysiology of $\mathrm{NaCwG}$ is still lacking.

Molecular genetic studies aimed to determine the factors contributing to the occurrence of $\mathrm{CwG}$. One study examined the association between $\mathrm{CwG}$ and channelopathy, as benign infantile convulsions were considered channelopathies by other molecular genetic studies. ${ }^{62-65)}$ However, no mutations in the neuronal sodium channel alpha 1 subunit (SCN1A) gene were identified in patients with $\left.\mathrm{CwG} .{ }^{66}\right)$ Mutations in the prolinerich transmembrane protein 2 (PRRT2) gene are known to cause benign familial infantile epilepsy, paroxysmal kinesigenic dyskinesia, and infantile convulsions with paroxysmal choreoathetosis. ${ }^{67-70)}$ However, no mutations in PRRT2 were found in CwG patients. ${ }^{71)} \mathrm{A}$ case report recently suggested that mutations in the alpha-II-spectrin (SPTAN1) gene, which is involved in earlyonset epileptic encephalopathy with progressive brain atrophy, severe intellectual disability with cerebellar malformations, and relatively milder phenotypes with or without epilepsy, were found in patients with $\mathrm{CwG} .{ }^{72)}$ Thus, more molecular genetic studies are required, including those on SPTAN1 gene mutations. 


\section{Biomarker for differential diagnosis}

An attempt was made to use S100B protein and neuronspecific enolase (NSE) as biomarkers. S100B is an intracellular calcium-binding protein that is dominant in astrocytes. ${ }^{73)}$ Several studies have suggested that serum S100B levels are associated with cerebral parenchymal damage. ${ }^{74-78)}$ NSE is a -y- subunit of enolase, a major component of the neuronal cytosol. ${ }^{79}$ Chen et al. ${ }^{22)}$ compared serum S100B and NSE protein levels in 46 patients with $\mathrm{CwG}$ versus 35 patients with febrile convulsions. They found that serum NSE levels were significantly higher in the $\mathrm{CwG}$ group than in the febrile seizure group; however, S100B levels were not significantly different. This feature was not associated with the number of convulsions or total convulsion duration in the $\mathrm{CwG}$ or febrile seizure groups. Therefore, the authors suggested that NSE could play a role in the differential diagnosis of $\mathrm{CwG}$ and febrile convulsions associated with mild gastroenteritis.

\section{Treatment and prognosis}

Several studies aimed to identify well-tolerated antiepileptic drugs in the acute phase of $\mathrm{CwG}$. One randomized, single-blind, placebo-controlled trial suggested the efficacy of intravenous phenobarbital $10 \mathrm{mg} / \mathrm{kg} .{ }^{20)}$ However, another study compared phenobarbital to lidocaine and showed a significantly higher efficacy for the latter. ${ }^{80)}$ Another study reported that 1-day treatment with carbamazepine or lidocaine effectively treated clustering seizures in $\mathrm{CwG} .{ }^{81)}$ Similarly, another study showed that 1-day treatment with low-dose carbamazepine was effective for $\mathrm{CwG} .{ }^{82)}$ Some studies demonstrated that fosphenytoin and chloral hydrate are also effective for $\mathrm{CwG}^{83}{ }^{834)}$ In addition, a recent study showed that a single dose of lacosamide was well tolerated in patients with $\mathrm{CwG} .{ }^{21)}$ Although clustering seizures frequently occur in the acute phase of $\mathrm{CwG}$, the prognosis is favorable, and antiepileptic therapy is not required after seizure cessation.

\section{Conclusions}

$\mathrm{CwG}$ is an afebrile seizure associated with mild gastroenteritis that occurs during healthy infancy and early childhood. Rotavirus and norovirus are its main causative pathogens. After the introduction of the rotavirus vaccine, the prevalence of $\mathrm{CwG}$ did not decrease, whereas that of $\mathrm{NaCwG}$ has increased annually. CwG is characterized as a generalized cluster seizure for which EEG and MRI show transiently abnormal findings that normalize. Some differential features were found in the clinical manifestation, EEG, and MRI findings between RaCwG and $\mathrm{NaCwG}$. Its pathophysiology remains unclear; however, there is evidence of direct or indirect effects of pathogens on the CNS. Recent efforts have been made to design biomarkers for the differential diagnosis of $\mathrm{CwG}$ and other convulsions. Some antiepileptic drugs are effective in the acute phase of $\mathrm{CwG}$, and long-term treatment is usually not required. Further studies are necessary to determine the pathogenesis of $\mathrm{CwG}$, and continuous monitoring of epidemiological changes is required.

\section{Footnotes}

Conflicts of interest: No potential conflict of interest relevant to this article was reported.

Funding: This study received no specific grant from any funding agency in the public, commercial, or not-for-profit sectors.

ORCID:

Yeong Seok Lee $\odot$ https://orcid.org/0000-0002-1055-6876

Ga Hee Lee @ https://orcid.org/0000-0002-9766-7914

Young Se Kwon (1) https://orcid.org/0000-0003-4570-7037

Author contribution: Conceptualization: YSK; Data curation: YSL; Formal analysis: YSL and GHL; Methodology: YSL and GHL; Project administration: YSK; Visualization: YSL; Writing - original draft: YSL; Writing - review \& editing: YSK

\section{References}

1. Centers for Disease Control and Prevention. Rotavirus. In: Hamborsky J, Kroger A, Wolfe S, editors. Epidemiology and prevention of vaccinepreventable diseases. 13th ed. Washington, DC: Public Health Foundation, 2015:311-22.

2. Liu L, Oza S, Hogan D, Perin J, Rudan I, Lawn JE, et al. Global, regional, and national causes of child mortality in 2000-13, with projections to inform post-2015 priorities: an updated systematic analysis. Lancet 2015;385:430-40.

3. Ito S, Takeshita S, Nezu A, Aihara Y, Usuku S, Noguchi Y, et al. Norovirusassociated encephalopathy. Pediatr Infect Dis J 2006;25:651-2.

4. Wong CJ, Price Z, Bruckner DA. Aseptic meningitis in an infant with rotavirus gastroenteritis. Pediatr Infect Dis J 1984;3:244-5.

5. Ushijima H, Bosu K, Abe T, Shinozaki T. Suspected rotavirus encephalitis. Arch Dis Child 1986;61:692-4.

6. Nakagomi T, Nakagomi O. Rotavirus antigenemia in children with encephalopathy accompanied by rotavirus gastroenteritis. Arch Virol 2005;150:1927-31.

7. Wong V. Acute gastroenteritis-related encephalopathy. J Child Neurol 2001;16:906-10.

8. Morooka K. Convulsions and mild diarrhea. Shonika 1982;23:131-7.

9. Komori H, Wada M, Eto M, Oki H, Aida K, Fujimoto T. Benign convulsions with mild gastroenteritis: a report of 10 recent cases detailing clinical varieties. Brain Dev 1995; 17:334-7.

10. Hung JJ, Wen HY, Yen MH, Chen HW, Yan DC, Lin KL, et al. Rotavirus gastroenteritis associated with afebrile convulsion in children: clinical analysis of 40 cases. Chang Gung Med J 2003;26:654-9.

11. Uemura N, Okumura A, Negoro T, Watanabe K. Clinical features of benign convulsions with mild gastroenteritis. Brain Dev 2002;24:745-9.

12. Kim DH, Lee YS, Ha DJ, Chun MJ, Kwon YS. Epidemiology of rotavirus gastroenteritis and rotavirus-associated benign convulsions with mild gastroenteritis after the introduction of rotavirus vaccines in South Korea: nationwide data from the health insurance review and assessment service. 
Int J Environ Res Public Health 2020;17:8374.

13. Kim DH, Ha DJ, Lee YS, Chun MJ, Kwon YS. Benign convulsions with mild rotavirus and norovirus gastroenteritis: nationwide data from the health insurance review and assessment service in South Korea. Children (Basel) 2021;8:263.

14. Kim BR, Choi GE, Kim YO, Kim MJ, Song ES, Woo YJ. Incidence and characteristics of norovirus-associated benign convulsions with mild gastroenteritis, in comparison with rotavirus ones. Brain Dev 2018;40: 699-706.

15. Kim GH, Byeon JH, Lee DY, Jeong HJ, Eun BL. Norovirus in benign convulsions with mild gastroenteritis. Ital J Pediatr 2016;42:94.

16. Verrotti A, Nanni G, Agostinelli S, Parisi P, Capovilla G, Beccaria F, et al. Benign convulsions associated with mild gastroenteritis: a multicenter clinical study. Epilepsy Res 2011;93:107-14.

17. Durá-Travé T, Yoldi-Petri ME, Gallinas-Victoriano F, Molins-Castiella T. Infantile convulsions with mild gastroenteritis: a retrospective study of 25 patients. Eur J Neurol 2011;18:273-8.

18. Lloyd MB, Lloyd JC, Gesteland PH, Bale JF. Rotavirus gastroenteritis and seizures in young children. Pediatr Neurol 2010;42:404-8.

19. Lee YS, Kim DH, Ha DJ, Kwon YS. Comparison of the demographics and ratio of rotavirus-associated benign convulsions with mild gastroenteritis to rotavirus gastroenteritis before and after rotavirus vaccination over a period of 20 years. Ann Child Neurol 2021;29:75-82.

20. Takami Y, Nakagawa T. Efficacy of phenobarbital for benign convulsions with mild gastroenteritis: a randomized, placebo-controlled trial. Brain Dev 2019;41:600-3.

21. Numoto S, Kurahashi H, Iwayama H, Okumura A. A trial of lacosamide for benign convulsions with gastroenteritis. Brain Dev 2020;42:551-4.

22. Chen H, Chen Y, Zhong JM. Detection and diagnostic value of serum NSE and S100B protein levels in patients with seizures associated with mild gastroenteritis. Medicine 2020;99:e23439.

23. Kang B, Kim DH, Hong YJ, Son BK, Kim DW, Kwon YS. Comparison between febrile and afebrile seizures associated with mild rotavirus gastroenteritis. Seizure 2013;22:560-4.

24. Chan CV, Chan CD, Ma C, Chan H. Norovirus as cause of benign convulsion associated with gastro-enteritis. J Paediatr Child Health 2011; 47:373-7.

25. Kawano G, Oshige K, Syutou S, Koteda Y, Yokoyama T, Kim BG, et al. Benign infantile convulsions associated with mild gastroenteritis: a retrospective study of 39 cases including virological tests and efficacy of anticonvulsants. Brain Dev 2007;29:617-22.

26. You SJ. Older patients may have more frequent seizures among children diagnosed as benign convulsions with mild gastroenteritis. Neuropediatrics 2020;51:354-8.

27. Caraballo RH, Gañez L, Santos CD los, Espeche A, Cersósimo R, Fejerman N. Benign infantile seizures with mild gastroenteritis: Study of 22 patients. Seizure 2009;18:686-9.

28. Cusmai R, Jocic-Jakubi B, Cantonetti L, Japaridze N, Vigevano F. Convulsions associated with gastroenteritis in the spectrum of benign focal epilepsies in infancy: 30 cases including four cases with ictal EEG recording. Epileptic Disord 2010;12:255-61.

29. Chae SH, Rhee M, Kim YC, Kim SS. The relationship between serum uric acid level and benign convulsions with mild gastroenteritis. J Korean Child Neurol Soc 2014;22:191-4.

30. Narchi H. Benign afebrile cluster convulsions with gastroenteritis: an observational study. BMC Pediatr 2004;4:2.

31. Wu YZ, Liu YH, Tseng CM, Tseng YH, Chen TH. Comparison of clinical characteristics between febrile and afebrile seizures associated with acute gastroenteritis in childhood. Front Pediatr 2020;8:167.

32. Chen B, Cheng M, Hong S, Liao S, Ma J, Li T, et al. Clinical outcome of recurrent afebrile seizures in children with benign convulsions associated with mild gastroenteritis. Seizure 2018;60:110-4.

33. Zhang T, Ma J, Gan X, Xiao N. Are afebrile seizures associated with minor infections a single seizure category? A hospital-based prospective cohort study on outcomes of first afebrile seizure in early childhood. Epilepsia 2014;55:1001-8.

34. Ma X, Luan S, Zhao Y, Lv X, Zhang R. Clinical characteristics and follow- up of benign convulsions with mild gastroenteritis among children. Medicine 2019;98:e14082.

35. Lee JY, Ryu JM, Lee JS, Ko TS, Yum MS. Clinical implications of ketosis in children with benign convulsions with mild gastroenteritis. J Clin Neurol 2020;16:96-101.

36. Ogawa C, Kidokoro H, Ishihara N, Tsuji T, Kurahashi H, Hattori A, et al. Splenial lesions in benign convulsions with gastroenteritis associated with rotavirus infection. Pediatr Neurol 2020;109:79-84.

37. Yoo SY, Kim DH, Lee Y, Lee GH, Ha DJ, Kwon YS. Serum uric acid as a predictive factor for rotaviral or noroviral benign convulsions with mild gastroenteritis. Ann Child Neurol 2020;28:138-44.

38. Yeom JS, Kim YS, Park JS, Seo JH, Park ES, Lim JY, et al. Role of Ca2+ homeostasis disruption in rotavirus-associated seizures. J Child Neurol 2014;29:331-5.

39. Natsume J, Naiki M, Yokotsuka T, Sofue A, Ikuta T, Kondo Y, et al. Transient splenial lesions in children with "benign convulsions with gastroenteritis." Brain Dev 2007;29:519-21.

40. Jiang L, Mao S, Xu J, Gao F. Reversible splenial lesion syndrome in children with benign convulsions associated with mild gastroenteritis: a retrospective study of five cases. Brain Dev 2019;41:271-5.

41. Mazur-Melewska K, Jonczyk-Potoczna K, Szpura K, Biegański G, Mania A, Kemnitz P, et al. Transient lesion in the splenium of the corpus callosum due to rotavirus infection. Childs Nerv Syst 2015;31:997-1000.

42. Jang YY, Lee KH. Transient splenial lesion of the corpus callosum in a case of benign convulsion associated with rotaviral gastroenteritis. Korean J Pediatr 2010;53:859-62.

43. Tada H, Takanashi J, Barkovich AJ, Oba H, Maeda M, Tsukahara H, et al. Clinically mild encephalitis/encephalopathy with a reversible splenial lesion. Neurology 2004;63:1854-8.

44. Hashino A, Saitoh M, Oka A, Okumura A, Kubota M, Saito Y, et al. Epidemiology of acute encephalopathy in Japan, with emphasis on the association of viruses and syndromes. Brain Dev 2012;34:337-43.

45. Kashiwagi M, Tanabe T, Shimakawa S, Nakamura M, Murata S, Shabana $\mathrm{K}$, et al. Clinico-radiological spectrum of reversible splenial lesions in children. Brain Dev 2014;36:330-6.

46. Bartolini L, Mardari R, Toldo I, Calderone M, Battistella PA, Laverda $\mathrm{AM}$, et al. Norovirus gastroenteritis and seizures: an atypical case with neuroradiological abnormalities. Neuropediatrics 2011;42:167-9.

47. Yang HR, Jee YM, Ko JS, Seo JK. Detection and genotyping of viruses detected in children with benign afebrile seizures associated with acute gastroenteritis. Pediatr Gastroenterol Hepatol Nutr 2009;12:183-93.

48. Choi JH, Kim JM, Kim YJ, Oh JW, Kim CL, Yum MK, et al. Genotype of rotavirus isolated from patients with rotaviral enteritis and neurological complications. Clin Exp Pediatr 2006;49:513-8.

49. Liu B, Fujita Y, Arakawa C, Kohira R, Fuchigami T, Mugishima H, et al. Detection of rotavirus RNA and antigens in serum and cerebrospinal fluid samples from diarrheic children with seizures. Jpn J Infect Dis 2009; 62:279-83.

50. Nishimura S, Ushijima H, Nishimura S, Shiraishi H, Kanazawa C, Abe T, et al. Detection of rotavirus in cerebrospinal fluid and blood of patients with convulsions and gastroenteritis by means of the reverse transcription polymerase chain reaction. Brain Dev 1993;15:457-9.

51. Blutt SE, Kirkwood CD, Parreño V, Warfield KL, Ciarlet M, Estes MK, et al. Rotavirus antigenaemia and viraemia: a common event? Lancet 2003;362:1445-9.

52. Weclewicz K, Svensson L, Kristensson K. Targeting of endoplasmic reticulum-associated proteins to axons and dendrites in rotavirus-infected neurons. Brain Res Bull 1998;46:353-60.

53. Díaz Y, Chemello ME, Peña F, Aristimuño OC, Zambrano JL, Rojas H, et al. Expression of nonstructural rotavirus protein NSP4 mimics Ca2+ homeostasis changes induced by rotavirus infection in cultured cells. J Virol 2008;82:11331-43.

54. Yeom JS, Kim YS, Jun JS, Do HJ, Park JS, Seo JH, et al. NSP4 antibody levels in rotavirus gastroenteritis patients with seizures. Eur J Paediatr Neurol 2017;21:367-73.

55. Medici MC, Abelli LA, Dodi I, Dettori G, Chezzi C. Norovirus RNA in the blood of a child with gastroenteritis and convulsions-a case report. J 
Clin Virol 2010;48:147-9.

56. Chung YJ, Lee KC, Kim GH, Eun SH, Eun BL, Byeon JH. Norovirus associated cerebellitis in a previous healthy 2-year-old girl. J Korean Child Neurol Soc 2017;25:179-82.

57. Obinata K, Okumura A, Nakazawa T, Kamata A, Niizuma T, Kinoshita $\mathrm{K}$, et al. Norovirus encephalopathy in a previously healthy child. Pediatr Infect Dis J 2010;29:1057-9.

58. Greenberg HB, Estes MK. Rotaviruses: from pathogenesis to vaccination. Gastroenterology 2009;136:1939-51.

59. Shaw DP, Morehouse LG, Solorzano RF. Rotavirus replication in colostrum-fed and colostrum-deprived pigs. Am J Vet Res 1989;50:196670.

60. Kawashima H, Inage Y, Ogihara M, Kashiwagi Y, Takekuma K, Hoshika A, et al. Serum and cerebrospinal fluid nitrite/nitrate levels in patients with rotavirus gastroenteritis induced convulsion. Life Sci 2004;74:1397-405.

61. Morichi S, Urabe T, Morishita N, Takeshita M, Ishida Y, Oana S, et al. Pathological analysis of children with childhood central nervous system infection based on changes in chemokines and interleukin 17 family cytokines in cerebrospinal fluid. J Clin Lab Anal 2018;32:e22162.

62. Specchio N, Vigevano F. The spectrum of benign infantile seizures. Epilepsy Res 2006;70:156-67.

63. Guipponi M, Rivier F, Vigevano F, Beck C, Crespel A, Echenne B, et al. Linkage mapping of benign familial infantile convulsions (BFIC) to chromosome 19q. Hum Mol Genet 1997;6:473-7.

64. Malacarne M, Gennaro E, Madia F, Pozzi S, Vacca D, Barone B, et al. Benign familial infantile convulsions: mapping of a novel locus on chromosome $2 \mathrm{q} 24$ and evidence for genetic heterogeneity. Am J Hum Genet 2001;68:1521-6.

65. Caraballo R, Pavek S, Lemainque A, Gastaldi M, Echenne B, Motte J, et al. Linkage of benign familial infantile convulsions to chromosome 16p12-q12 suggests allelism to the infantile convulsions and choreoathetosis syndrome. Am J Hum Genet 2001;68:788-94.

66. Weng WC, Hirose S, Lee WT. Benign convulsions with mild gastroenteritis: is it associated with sodium channel gene SCN1A mutation? J Child Neurol 2010;25:1521-4.

67. Scheffer IE, Grinton BE, Heron SE, Kivity S, Afawi Z, Iona X, et al. PRRT2 phenotypic spectrum includes sporadic and fever-related infantile seizures. Neurology 2012;79:2104-8.

68. Becker F, Schubert J, Striano P, Anttonen AK, Liukkonen E, Gaily E, et al. PRRT2-related disorders: further PKD and ICCA cases and review of the literature. J Neurol 2013;260:1234-44.

69. Yang X, Zhang Y, Xu X, Wang S, Yang Z, Wu Y, et al. Clinical features and PRRT2 mutations in infantile convulsions with paroxysmal choreoathetosis. Zhonghua Yi Xue Yi Chuan Xue Za Zhi Zhonghua Yixue Yichuanxue Zazhi Chin J Med Genet 2014;31:679-85.

70. Yang X, Zhang Y, Xu X, Wang S, Yang Z, Wu Y, et al. Phenotypes and PRRT2 mutations in Chinese families with benign familial infantile epilepsy and infantile convulsions with paroxysmal choreoathetosis. BMC Neurol 2013;13:209.

71. Ishii A, Yasumoto S, Ihara Y, Inoue T, Fujita T, Nakamura N, et al. Genetic analysis of PRRT2 for benign infantile epilepsy, infantile convulsions with choreoathetosis syndrome, and benign convulsions with mild gastroenteritis. Brain Dev 2013;35:524-30.
72. Terrone G, Pinelli M, Bernardo P, Parrini E, Imperati F, Brunetti-Pierri N, et al. Intrafamilial variability in SPTAN1-related disorder: from benign convulsions with mild gastroenteritis to developmental encephalopathy. Eur J Paediatr Neurol 2020;28:237-9.

73. Tsoporis JN, Mohammadzadeh F, Parker TG. Intracellular and extracellular effects of S100B in the cardiovascular response to disease. Cardiovasc Psychiatry Neurol 2010;2010:1-6.

74. Donato R, Sorci G, Riuzzi F, Arcuri C, Bianchi R, Brozzi F, et al. S100B's double life: intracellular regulator and extracellular signal. Biochim Biophys Acta 2009;1793:1008-22.

75. Pleines UE, Morganti-Kossmann MC, Rancan M, Joller H, Trentz O, Kossmann T. S- $100 \beta$ reflects the extent of injury and outcome, whereas neuronal specific enolase is a better indicator of neuroinflammation in patients with severe traumatic brain injury. J Neurotrauma 2001;18:4918.

76. Thompson WH, Thelin EP, Lilja A, Bellander BM, Fransson P. Functional resting-state fMRI connectivity correlates with serum levels of the S100B protein in the acute phase of traumatic brain injury. NeuroImage Clin 2016;12:1004-12.

77. Chaparro-Huerta V, Flores-Soto ME, Merin Sigala ME, Barrera de León JC, Lemus-Varela ML, Torres-Mendoza BM, et al. Proinflammatory Ccytokines, Eenolase and S-100 as early biochemical indicators of hypoxic-ischemic encephalopathy following perinatal asphyxia in newborns. Pediatr Neonatol 2017;58:70-6.

78. Romner B, Ingebrigtsen T, Kongstad P, Børgesen SE. Traumatic brain damage: serum S-100 protein measurements related to neuroradiological findings. J Neurotrauma 2000;17:641-7.

79. Kato K, Suzuki F, Umeda Y. Highly sensitive immunoassays for three forms of rat brain enolase. J Neurochem 1981;36:793-7.

80. Okumura A, Uemura N, Negoro T, Watanabe K. Efficacy of antiepileptic drugs in patients with benign convulsions with mild gastroenteritis. Brain Dev 2004;26:164-7.

81. Tanabe T, Okumura A, Komatsu M, Kubota T, Nakajima M, Shimakawa S. Clinical trial of minimal treatment for clustering seizures in cases of convulsions with mild gastroenteritis. Brain Dev 2011;33:120-4.

82. Kikuchi K, Hamano S, Matsuura R, Tanaka M, Minamitani M. Effects of various antiepileptic drugs in benign infantile seizures with mild gastroenteritis. Epilepsy Seizure 2017;9:25-31.

83. Enoki H, Yokota T, Nagasaki R, Ohro Y, Takeda S, Nakashima Y, et al. Single-dose chloral hydrate for benign convulsions with mild gastroenteritis. Epilepsia 2007;48:1026-8.

84. Nakazawa M, Toda S, Abe S, Ikeno M, Igarashi A, Nakahara E, et al. Efficacy and safety of fosphenytoin for benign convulsions with mild gastroenteritis. Brain Dev 2015;37:864-7.

How to cite this article: Lee YS, Lee GH, Kwon YS. Update on benign convulsions with mild gastroenteritis. Clin Exp Pediatr 2022;65:469-75. https://doi.org/10.3345/cep.2021. 00997 